\title{
8
}
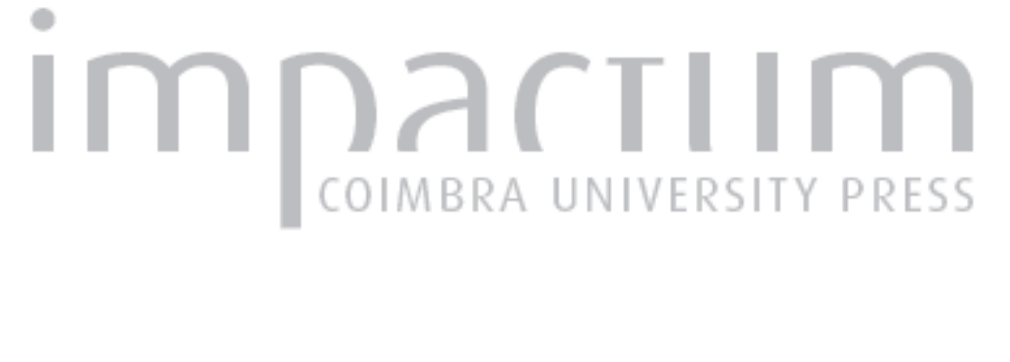

\section{O fascínio da miragem: encontros de cultura e viagens contemporâneas de portugueses a Itália}

Autor(es): $\quad$ Ferro, Manuel

Publicado por: Imprensa da Universidade de Coimbra

URL persistente:

URI:http://hdl.handle.net/10316.2/42391

DOI:

DOI:https://doi.org/10.14195/0870-8584_10_5

Accessed : $\quad$ 26-Apr-2023 10:54:59

A navegação consulta e descarregamento dos títulos inseridos nas Bibliotecas Digitais UC Digitalis, UC Pombalina e UC Impactum, pressupõem a aceitação plena e sem reservas dos Termos e Condições de Uso destas Bibliotecas Digitais, disponíveis em https://digitalis.uc.pt/pt-pt/termos.

Conforme exposto nos referidos Termos e Condições de Uso, o descarregamento de títulos de acesso restrito requer uma licença válida de autorização devendo o utilizador aceder ao(s) documento(s) a partir de um endereço de IP da instituição detentora da supramencionada licença.

Ao utilizador é apenas permitido o descarregamento para uso pessoal, pelo que o emprego do(s) título(s) descarregado(s) para outro fim, designadamente comercial, carece de autorização do respetivo autor ou editor da obra.

Na medida em que todas as obras da UC Digitalis se encontram protegidas pelo Código do Direito de Autor e Direitos Conexos e demais legislação aplicável, toda a cópia, parcial ou total, deste documento, nos casos em que é legalmente admitida, deverá conter ou fazer-se acompanhar por este aviso.

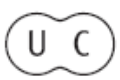




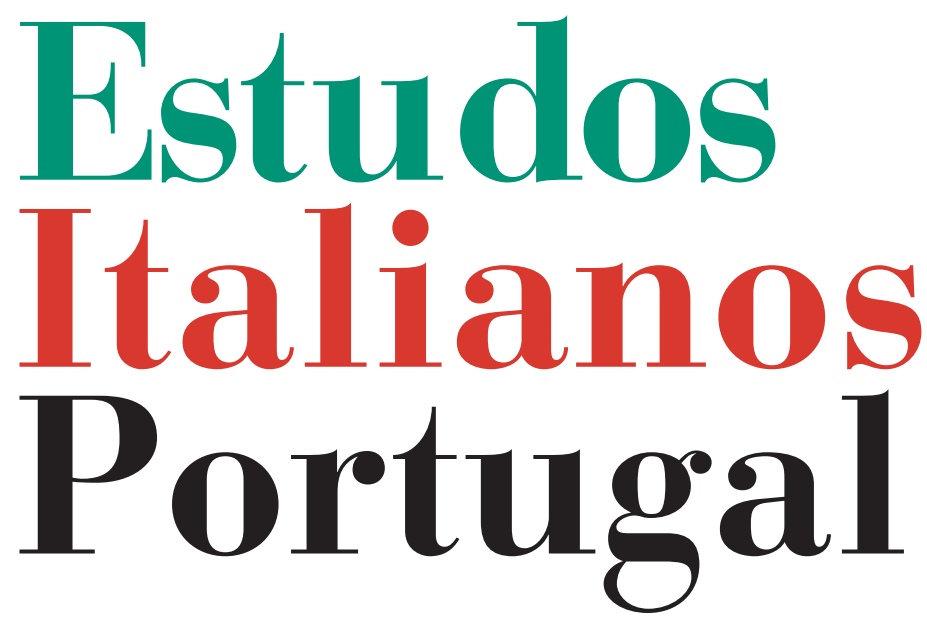

Instituto

Italiano

de Cultura

de Lisboa

Nova Série

$\mathrm{N}^{\mathbf{0}} 10$

2015 


\section{O FASCÍNIO DA MIRAGEM. ENCONTROS \\ DE CULTURA E VIAGENS CONTEMPORÂNEAS DE PORTUGUESES A ITÁLIA}

MANUEl FERro*

NesTes TEMPOS de encontros (e alguns desencontros), em que o diálogo se estabelece à escala planetária da aldeia global e o passado se cruza com o presente, ao mesmo tempo que culturas e civilizações contemporâneas interactuam em amena simbiose ou colidem frontalmente, o certo é que, neste contexto, a Itália sempre constituiu um polo de fascínio e atracção para os portugueses. Essa atitude exprime-se mesmo em termos hiperbólicos, traduzidos pela retórica mais trivial, mas ainda assim apelativa, dos catálogos dos operadores de viagens que a colocam entre os mais conceituados destinos de sonho.

Sonho, charme, paixão, monumentalidade, fascínio, sedução, eis, pois, termos-chave fundamentais usados para definir esse arrebatamento que nos liga a um país donde sentimos provirem as matrizes da nossa cultura e identidade. Desde os tempos do império romano aos das manifestaçôes literárias e artísticas do Renascimento, passando por aspectos porventura menos relevantes como a música ou até as ideias políticas, jurídicas e religiosas, o certo é que todos esses factores contribuem para que em Itália os portugueses jamais se sintam estrangeiros. E por isso mesmo se deixam enlevar com

\footnotetext{
* Professor da Faculdade de Letras da Universidade de Coimbra.
} 
circuitos clássicos que os conduzem a vislumbrar uma Itália monumental, de Roma a Nápoles, Capri, Sorrento, Pompeia, Florença e Veneza; ou partindo de Milão e seguindo por Verona, Pádua, Pisa, Siena e Assis; ou ainda quando são estimulados a admirar as cores da Sicília, de Palermo a Agrigento, Siracusa, Taormina e Catânia...

Traduzem-se, assim, as expectativas de quantos vão ao encontro dos seus sonhos, despoletando a activação de conceitos ou preconceitos extraliterários ${ }^{1}$, mediante o recurso a estratégias de ordem estética, sociológica, política ou etnológica $^{2}$, ou identificando clichés ${ }^{3}$, modelos ou imagens, eventualmente deturpadas ${ }^{4}$, que sempre integraram os modos de representação que os portugueses construíram de outras naçôes e povos, e, naturalmente, da Itália e da cultura italiana. Confrontando-nos agora com esses relatos, urge recorrer a pressupostos enunciados nos estudos de um Hugo Dyserinck ${ }^{5}$, um Peter Boerner, um Hörst Rüdiger ou um Manfred

${ }^{1}$ Cf. Hugo Dyserinck, "Komparatistische Imagologie jenseits von 'Werkimmanenz' und 'Werktranszendenz', Synthesis. Bulletin du comité national de littérature comparée de la République Socialiste de Roumanie, 9, 1982, pp. 27-40.

2 Id., 'Zum Problem der 'images' und 'mirages' und ihrer Untersuchung im Rahmen der Vergleichenden Literaturwissenschaft”, pp. 110-111, Arcadia. Zeitschrift für Vergleichende Literaturwissenschaft, 1, 1966, pp. 107-120.

${ }^{3}$ Cf. Hörst Rüdiger, Literarisches Klischée und lebendige Erfahrung, Düsseldorf, 1971. Refere que, devido ao facto de a imagem de um povo ou de um país se enriquecer com traços específicos da imaginação do escritor, outros factores, de ordem psicológica, sociológica e política, influem no processo de transformação da imagem em miragem e desta em mito. Mostra como os alemães olharam os italianos, e vice-versa, ao longo dos séculos, apontando as obras e autores que mais contribuíram para o estabelecimento de clichés, que aderiram à imagem dos dois povos.

${ }^{4}$ Cf. Peter Boerner, "Bas Bild vom anderen Land als Gegenstand literarischer Forschung”, Sprache und Technischen Zeitalter, 56, 1975, pp. 313-321.

${ }^{5}$ Relevemos, entre outros, "Komparatistische Imagologie. Zur politischen Tragweite einer europäischen Wissenschaft von der Literatur", in Hugo Dyserinck und Karl Ulrich Syndram (Hrsg.), Europa und das Selbstverständnis. Imagologische Probleme in Literatur, Kunst und Kultur des 19. Und 20. Jahrhunderts, Bonn, 1988, onde aborda a questão da imagologia comparada numa perspectiva europeia, pelo facto de este 
Fischer no âmbito da imagologia ${ }^{6}$, fundamentando uma abordagem textual que se insere dentro dos contornos dos Estudos Culturais ${ }^{7}$ ou, em sentido mais amplo, da Literatura Comparada $^{8}$. Avalia-se a imagem mais ou menos literária que os produtores dos relatos tecem de Itália e dos italianos, de modo a influenciar o leitor, levando-o a apreciar o país em causa e a respectiva cultura, e trazendo para o campo da literatura aspectos extraliterários, que se revestem de um

Continente ser marcado pela sua multinacionalidade e multiculturalidade. Assim, as imagens do estrangeiro devem assumir uma posição supranacional e constituir uma área ideologicamente neutra no contexto das relações multinacionais. Esboça a relação existente entre consciência nacional e consciência europeia, na esteira do que M.me de Staël designava por l'esprit européen, e problematiza conceitos como eigene Charakterzüge, que contrapóe a Volksseele e Nationalcharakter, aproximando-os do de Völkerspsychologie. Relativiza-os, então, face ao respectivo contexto histórico que os havia delimitado. Só então trata da noção de 'nacionalidade' (Nationalgefühl e $\mathrm{Na}$ tionalbewußtsein). Aponta ainda a diferença entre Hetero- e Autoimagebildung (como forma de autoconsciência nacional) e o modo como os traços nacionais referidos aí se projectam.

6 "L'étranger tel qu'on le voit", de Marius-François Guyard, em La littérature comparée, Paris, PUF, 31961, pp. 110-119, é comummente aceite como o terminus a quo para a nova fase de estudos desta área. Tal facto não invalida que anteriormente não tivessem existido contributos esclarecedores e criteriosos sobre esta matéria. Citem-se as declarações de Louis Paul Betz, de 1896, que considera ser tarefa fundamental desta área de investigação "nachzuforschen, wie sich die Nationen untereinander umgeschaut haben, nehmen oder verwerfen, nachahmen oder entstellen, verstehen oder nicht verstehen, sich gegenseitig ihre Herzen eröffnen oder verschließen" (L. P. Betz, "Kritische Betrachtungen über Wesen, Aufgaben und Bedeutung der vergleichenden Literaturgeschichte", Zeitschrift für französische Sprache und Literatur, 1896, 18, p. 151).

${ }^{7}$ Por ex., Armand Mattelart e Érik Neveu, Introdução aos estudos culturais, Porto, 2006; Ziauddin Sardar and Borin van Loon, Introducing cultural studies. A graphic guide, London, 2010.

${ }^{8}$ São de referir os seguintes títulos, que tratam directamente da imagologia ou a contextualizam no âmbito da Literatura Comparada: Álvaro Manuel Machado e Daniel-Henri Pageaux, Da literatura comparada à teoria da literatura, Lisboa, 1988; Yves Chevrel, "L'image de l'étranger", La littérature comparée, Paris, 1989, pp. 2526; Antoni Maczak, Viaggi e viaggiatori nell'Europa moderna, Roma-Bari, 1992; Ana Margarida Falcão, Maria Teresa Nascimento e Maria Luísa Leal (coord.), Literatura de viagem. Narrativa, história, mito, Lisboa, 1997; Fernando Cristóvão (coord.), Con- 
valor hermenêutico mais profundo ${ }^{9}$. Oscilando entre o relato referencial ${ }^{10}$, jornadas imaginárias e viagens iniciáticas ${ }^{11}$, esse diálogo de culturas assume formas diversas, desde apontamentos de viagem ${ }^{12}$ a livros carregados de erudição ${ }^{13}$, roteiros de turismo ${ }^{14}$ ou até trocas de correspondência ${ }^{15}$.

Os relatos de viagens mais recentes, produto de uma mundivisão pós-moderna, associam-se a outras estratégias de carácter literário. Nuns, seguem-se técnicas colhidas da escrita autobiográfica, em que o pacto referencial e o pacto autobiográfico surgem mais ou menos camuflados; noutros, sucumbe-se aos códigos da ficção narrativa e do romance histórico, em particular.

Depois de um século de turismo de massas, revisitam-se e reabilitam-se inevitavelmente, e de modo crítico, lugarescomuns presentes na tradição dos relatos de viagem a Itália

dicionantes culturais da literatura de viagens. Estudos e bibliografias, Coimbra, 2002. Sobre a articulação do estudo da imagem dos países ou culturas nacionais com o do mito literário, veja-se Daniel-Henri Pageaux, "Une Perspective d'Études en Littérature Comparée: L'Imagerie Culturelle”, Synthesis, 8, 1981, pp. 169-185.

${ }^{9}$ Cf. Manfred S. Fischer, "Komparatistische Imagologie. Für eine interdisziplinäre Erforschung national imagotyper Systeme”, Zeitschrift für Sozialpsychologie, 10, 1979, pp. 30-44.

${ }^{10}$ Cf., p. ex., Gaspar Barreiros, Chorographia..., Coimbra, 1968 (1561).

${ }^{11}$ Consultem-se Justino de Montalvão, Itália coroada de rosas, Rio de Janeiro, Livraria Garnier, 1910; Manuel Ribeiro, A revoada dos anjos, Lisboa, 1926; Artur Portela, Rosas de Itália, Lisboa, s. d.; Marques Gastão, Romagem a Itália, Lisboa, 1956.

${ }^{12}$ Ver os apontamentos de dois clérigos de Coimbra na obra de Maria Helena da Cruz Coelho e Maria José Azevedo Santos, De Coimbra a Roma. Uma viagem em meados de Quinhentos, Coimbra, 1990, ou de D. Frei Alexandre da Sagrada Família, em Ofélia M. Caldas Paiva Monteiro, D. Frei Alexandre da Sagrada Família. A sua espiritualidade e a sua poética, Coimbra, 1974.

${ }^{13}$ Ver, de Carlos Santos, Como eu vi a Itália, Lisboa, 1928, ou, de Caetano Beirão, Via Latina. Viagens-História-Literatura, Lisboa, 1938.

${ }^{14}$ Cf. Carlos d'Ornellas, Viajando pela Europa. I. Itália, Lisboa, 1951, ou Luiz de Vasconcellos Arruda, Viagens. Volume III - Itália, Lisboa, 1952.

${ }^{15}$ Cf. do Abade António da Costa, Cartas curiosas escritas de Roma e Viena, Porto, 1878. 
do passado, que se assumem agora enriquecidos pela experiência vivida in loco. É assim que Roma. Exercícios de reconhecimento, de António Mega Ferreira ${ }^{16}$; Os dias de Veneza, de Eduardo Pitta ${ }^{17}$; e De Riba-Côa a Roma. Uma viagem no tempo de... 1676, de Alcides Gouveia ${ }^{18}$, tão diferentes entre si, apresentam denominadores comuns. É que as três obras são o produto não de um saber distante e livresco de tratados e relatos anteriores, mas de um conhecimento de causa fecundado pela presença do produtor do discurso no espaço representado, muito embora não esconda ser conduzido pela mão de autores de obras e títulos de natureza diversa, de escritores de referência já antes também mais ou menos conhecidos do leitor. Não admira, portanto, que o livro de Mega Ferreira abra com a magistral declaração:

Cada viajante constrói, das cidades que ama, uma ideia que raramente coincide com a lógica da geografia urbana. Na sua forma de amar uma cidade, desenha percursos, associações imaginárias, mitos instrumentais que o fazem ver as fachadas, os monumentos, as praças e as gentes de uma determinada zona como os melhores sinais identificadores do espírito do lugar. A sua noção de geografia é essencialmente afectiva, as suas preferências não são racionais, e, por isso, essa zona eleita figura no seu espírito, e para sempre, como o centro da cidade. Para mim, a Piazza della Rotonda e o Panteão são o verdadeiro centro de Roma.(p. 11)

Depois dessa exemplar declaração de amor que Mega Ferreira faz por Roma como por nenhuma outra cidade (p. 12), sente o autor a necessidade de se justificar, já que ali revê um

${ }^{16}$ António Mega Ferreira, Roma. Exercícios de reconhecimento, Porto, Sextante Editora, 2003. Utilizei a 3. ${ }^{\text {a }}$ edição, revista e aumentada, de 2010.

${ }^{17}$ Eduardo Pitta, Os dias de Veneza, Vila Nova de Famalicão, Quasi Edições, 2005.

${ }^{18}$ Alcides Gouveia, De Riba-Côa a Roma. Uma viagem no tempo de... 1676, Lisboa, Chiado Editora, 2014. 
espaço de síntese do saber e da estética das civilizações anteriores, que só a cultura romana foi capaz de conseguir:

Num só lugar fundia o melhor da tradição grega, o pórtico monumental sustentado em dezasseis colunas de grandes dimensóes, com a lição da engenharia romana, e a projecção vertical do templo dava à horizontalidade visível no pórtico, que dominara a concepção helénica dos lugares de culto, uma dimensão que antecipava, em muitos séculos, a arquitectura sacra do cristianismo. Com Adriano, a fé, eclética como ele próprio a praticava, descobria o céu e buscava na luz do sol o alimento da esperança que a justificava.(p. 13)

Todavia, a par desse deslumbramento estético, é a fruição dos sentidos, do paladar, da visão, e até da sensualidade, quando não mesmo do erotismo, à mistura com as intuiçôes sentidas, que o conduzem pelos meandros da arte e da história e valorizam a sua peculiar visão da cidade:

Ali, sentada na base de uma coluna, imperturbável, vi um dia a comer um tramezzino, a mais bela mulher de Roma; perto, ficava um dos meus restaurantes preferidos, o Vecchia Locanda, onde em tempos se saboreava um formidável coelho recheado com trufas; a dois passos, ascende-se às alturas gustativas do Giolitti, onde se servem os mais famosos gelados de Roma; e dali, num pulo, vê-se Caravaggio em S. Luís dos Franceses, vai-se ao Campo dei Fiori apreçar as melancias colossais, desce-se ao largo da Torre Argentina para imaginar o lugar onde César foi assassinado. A minha Roma, que é vasta e se espraia por vinte séculos de arte e cultura, começa aqui, onde o rasto glorioso de Adriano se cruza com a sombra luminosa de Rafael.(p. 14)

A partir daquele espaço traçam-se as deambulações de alguém que se perde pelos Mercados de Trajano e pela Villa Adriana e reflecte sobre a passagem do tempo e os caprichos do destino: 
[...] Na placidez quase abrasiva de uma tarde de Verão, as ruínas do que foi o sonho de Adriano ecoam uma música suave de reminiscências, uma espécie de memória do futuro, figura da totalidade que encarna numa utopia anacrónica: a de um tempo em que o mundo voltasse a ser uma descoberta e a vida de cada um de nós a sua própria construção.(pp. 31-32)

Por outro lado, também não fica insensível aos primórdios do Cristianismo e é sobremaneira as reminiscências dos actos dos mártires dos primeiros séculos da nova era, perante a observação das catacumbas e outras manifestações da persistência na Fé, que lhe revelam a outra face da Cidade:

Roma revê-se nos seus mártires, da mesma forma que se olha ao espelho da glória pagã do Império. Nenhuma outra cidade é tão ostensivamente narcísica em relação ao seu passado; mas nenhuma outra, é verdade, se construiu em tão íntima sobreposição de heranças e testemunhos, pedras e memórias, mitos e crenças.(p. 35)

Mais adiante, já num registo ligeiramente diferente, pega em sugestóes que as leituras lhe proporcionam e perscruta os testemunhos que persistem em apontar curiosidades e pormenores que decerto passariam despercebidos ao olhar dum viajante menos atento:

Certos livros escorregam-nos entre os dedos: ou passam anos a fugir do nosso apetite de leitores, ou desprezam-nos em silêncio porque os ignoramos. Refiro-me aos livros que vamos acumulando, sem tempo para os ler. Mas um livro que entra na biblioteca é um livro que desejamos ler; o mais provável é dizermos para nós mesmos, no instante em que o compramos: há-de chegar o momento.(p. 55)

Sem dúvida que um desses livros é a obra de Goethe, Die Italienische Reise. E confronta o seu percurso com o da descoberta da cidade efectuada pelo escritor alemão há dois séculos 
atrás, mas que tanto em comum com a sua experiência ainda contém:

Na entrada relativa a 1 de Novembro de 1786 da sua Viagem a Itália, Goethe saúda a chegada a Roma com a seguinte evocação, que é também uma (re)descoberta: "Vejo agora como os sonhos da minha juventude ganham vida: as primeiras gravuras em cobre de que me lembro (o meu pai tinha vistas de Roma numa antecâmara), vejo-as agora em realidade, e tudo aquilo que eu já conhecia em quadros e desenhos, gravuras em cobre e madeira, em gesso e cortiça, está agora, tudo junto, à minha frente; para onde quer que vá encontro coisas conhecidas num mundo novo; é tudo como eu tinha imaginado, e tudo novo."

Mais de quarenta anos antes, também o pai de Goethe cedera à tentação do grand tour, que incluía, ao gosto setecentista, um giro de Itália, à procura dos sinais residuais da cultura clássica que ocupava o centro das referências eruditas das elites cultas do tempo.(p. 123)

Se, numa dada perspectiva, ainda é uma certa visão arqueológico-monumental da cidade que aí se transmite, também é verdade a indisfarçável volúpia, o alimento capaz de saciar a sua fome de absoluto, que o estimula a inventar um real ampliado pelo seu olhar curioso e inquieto (cf. p. 125). Por isso, a essa abordagem fundamentalmente visual da cidade, associa-se estreitamente a respectiva representação nas magníficas gravuras de Piranesi, que enriquecem o volume de Mega Ferreira passo a passo. E comenta:

Piranesi não se limitou, aliás, a desenhar ruínas: em alguns casos, partiu delas para uma reinvenção do seu estado original; em outros, acumulou fragmentos, inscriçôes, obeliscos e lápides funerárias, vasos e estátuas, símbolos e elementos alegóricos, em composiçōes que esgotam, por sobredeterminação, o sentido evocatório da ruína. [...] Há, nas vedute romanas de Piranesi, uma dimensão metafísica que as torna, simultaneamente, arquétipos de Roma, pela arquitectura, e 
rugas indisfarçáveis do tempo que passa, pela visão poética. A obra de Piranesi é uma meditação sobre o perecível e o eterno, entre a derruída aparência das coisas e a sua essência imperscrutável.(pp. 127-128)

Por tudo isso, Roma é mais do que paisagem. Por tudo quanto sugere e dá a conhecer ao viajante, é a própria alegoria da criação:

[...] Roma "é um arquétipo demasiado forte", como disse Yves Bonnefoy: tudo, na cidade, é estímulo à escrita, tudo é recurso aos sentidos, tudo exalta a criatividade. Admirem-se as suas ruínas; mas admirem-se, como dizia Stendhal, "imaginando o que falta e abstraindo do que existe”. Percorram-se as suas igrejas; mas não se esqueça que elas nascem de uma pulsão religiosa sem paralelo. Visitem-se os seus museus; mas não deixemos que a pressão da quantidade nos gaste o olhar para aquilo que é essencial, as obras supremas casualmente alinhadas com as dos seus epígonos. E há as ruas, a beleza da gente, o seu vozear cantado, as cores, o clima, os jardins, os terraços debruçados do alto dos prédios sobre o vazio; e as laranjeiras, as mil e uma espécies de pinheiros, as azáleas e as magnólias, "faluas brancas num mar de verde carregado", como escreveu o poeta Giuseppe Conte.(pp. 173-174)

Então, numa atitude metapoética, medita o viajante-escritor sobre a própria índole da obra que está em vias de concluir e mostra como o processo de epifania hermenêutica é sugestionada pelo devaneio resultante da deambulação pelo espaço que a Urbe lhe proporciona:

Este livro não descreve Roma: toma-a como pretexto para incursões em territórios que vivem comigo há muitos anos, seja o cinema italiano do pós-guerra ou a paixão da Tosca, a tragédia de Caravaggio ou a graça requintada de Rafael. E o meu longo fascínio, sempre ambivalente, pela arquitectura; o gosto pelas cenografias fantásticas de Bernini; a sugestão de uma grandeza impensável nas ruínas imperiais; o sonho de Adriano vazado nos restos da villa que fez construir nos 
arredores de Roma. Roma é uma tradição literária que conta mais do que se vê e uma tradição visual que nos mostra mais do que aquilo que qualquer literatura seria capaz de imaginar.(p. 174)

Confessa, pois, que, de fora, teriam ficado ainda outros textos à espera de melhores dias, sobre a Escola de Atenas de Rafael, bem como outros sobre um percurso pela Via di Ripetta, o vedutismo seiscentista e a campagna romana, o kitsch do bairro Coppedè, o tecto do Palazzo Barberini pintado por Pietro da Cortona e ainda outro sobre o mausoléu de Augusto. E conclui:

Este livro é um agradecimento, impessoal e indeterminado: viver faz todo o sentido, quando se conheceu Roma.(p. 175)

Por sua vez, Os Dias de Veneza, de Eduardo Pitta, ostenta uma estrutura diarística. Cada capítulo corresponde a uma jornada na cidade da laguna e, por isso, inicia-se com a indicação da respectiva data, de 12 de Setembro, domingo, a 16, quinta-feira, do mesmo mês de 2004. O volumito abre-se com uma epígrafe de Joseph Brodsky, de Watermark, em que se faz um apelo à componente visual do objecto da escrita:

Porque esta é a cidade do olhar; as nossas outras faculdades limitam-se a tocar um débil segundo violino [...] porque o olho, o nosso único órgão interno visível, pisciforme, pode aqui nadar deveras: sulca as águas, agita-se, oscila, mergulha, revira-se. A sua geleia exposta demora-se com um prazer atávico nos reflexos dos palazzi, nos saltos altos, nas gôndolas, etc., reconhecendo-se a si própria como a instância que os trouxe à superfície existencial.(p. 9)

Essa insistência no olhar recruta todo o conhecimento latente no leitor e evoca, na pintura setecentista, a escola dos vedutisti venezianos. Antonio Canal, o Canaletto, e Bernardo Bellotto souberam bem difundir, transformando quase num 
estereótipo, o tema da paisagem luminosa da laguna, procurando retratar, com precisão fotográfica, os momentos de exaltação nacional, vividos na cidade. Nas suas telas reproduzem-se as regatas, o Bucentauro diante do Palácio Ducal, a Praça de S. Marcos, o Canal Grande, as festas das Scuole, em suma, a Veneza ainda imperial e esplendorosa, que parece resistir à passagem do tempo, imponente, de grandes palácios construídos entre o céu e a água, tirados dos mais belos ângulos e numa atmosfera inundada de luz. Francesco Guardi, que trata igualmente a paisagem veneziana, leva a cabo a síntese nervosa da composição com os jogos de sombra e luz que alternam sobre ruínas e figuras, com manchas de cor que traduzem a poesia de um visionário. A paisagem lagunar, com as casas do seu povo, apresenta figuraçóes de acento nostálgico, já ao gosto pré-romântico. Mais inovador que os restantes, Guardi destaca-se pela sua técnica, feita de pinceladas breves e ricas que diluem as formas sólidas e os contornos. Mas a sua escolha temática também é afectiva, o que traduz em delicadas tonalidades de pérola, numa luminosidade difusa ${ }^{19}$. E viajar sobre as águas ou deambular pelas ilhas da cidade, é reviver com nostalgia a grandeza desgastada dos palácios, dos canais, das gôndolas, iluminados pelo luar. Mas o leitor não esquece, que, hoje, Veneza é a capital do turismo mundial, a cidade ameaçada, que se afunda continuamente na plataforma lamacenta da laguna e um dia, no futuro, qual Vineta submersa, dela só restarão os pináculos das torres das igrejas a servirem de marcos à navegação.

Fundado nessa tradição fundamentalmente de carácter pictórico e, por conseguinte, altamente sugestiva do ponto de vista visual, a viagem inicial, no livro de Eduardo Pitta é a da chegada, do aeroporto Marco Polo ao hotel, situado junto do Canal Grande, enumerando-se as ilhas de passagem, Tor-

${ }^{19}$ Cf. Manuel Ferro, O mito veneziano na obra de Hugo von Hofmannsthal, Coimbra, Faculdade de Letras, 1992. 
cello, Burano, Murano, Lido, San Giorgio Maggiore e a Giudeca. Ambientes de luxo e requinte evocam o passado glorioso da Sereníssima República. Mas, ao longo das páginas, não se trata da reconstituição do mito veneziano. Ele subjaz a todo o discurso do diário, está presente, é sabido, mas surge agora actualizado perante o que é dado a conhecer ao leitor através da experiência e observação do autor. Ele conduz-nos pela mão e mostra-nos que percorrer o Canal Grande é o mesmo que seguir o percurso iniciático necessário para podermos compreender o mistério do fascínio desta cidade. São os palácios sumptuosos, as pontes caprichosas, os fondachi, as igrejas, os jardins, os campi. S. Marcos destaca-se pela sua configuração original: ali é o Oriente, com toda a sua pujança, com todo o seu ouro, o seu colorido e a sobrecarga decorativa que nos deslumbra. Ao lado desta notável relíquia bizantina, é a majestosa arquitectura do palácio dos doges num gótico sui generis, veneziano mesmo, em branco e rosa que contrasta e se projecta no espelho azulado das águas dos canais. Depois, é a ala tardo-renascentista das Procuradorias, a Torre do Relógio e o campanário da catedral, que conferem à "piazza" o aspecto de um maravilhoso cenário de teatro, o ambiente de um salão de divertimentos ao ar livre. E, com o autor, o leitor revive a magia da cidade.

Visita-se o Florian, o Harry's e o Danieli. Recordam-se os nomes de artistas e escritores célebres que ali por passaram; reconstituem-se os requintes gastronómicos caros ao palato e referem-se outros restaurantes famosos, quer pelos pratos confecionados, quer pela decoração e pelos antigos frequentadores. A par de uma Veneza museológica, descobre-se outra comercial, de papelarias, livrarias e boutiques. E os dias esmorecem ao sabor da melodia dos clássicos populares interpretados pelas orquestras nas arcadas.

Rialto, Tiepolo, Donatello, Casanova constituem os primeiros tópicos do segundo dia, que acaba por nos conduzir ao Lido, com todas as implicaçóes suscitadas pela Morte em 
Veneza de Thomas Mann, para, no regresso, percorrermos a Riva degli Schiavoni e ainda nos perdermos entre as riquezas patentes ostensivamente no Palácio Ducal. Numa acumulação de alusóes a escritores, pintores, compositores e artistas de todo o género ligados a cada ângulo da cidade, andar à deriva por Veneza guiados por Eduardo Pitta torna-se uma experiência estetizante por excelência. Depois, é a Academia, o Ca Rezzonico (fechado, por sinal, na altura), La Fenice e um cruzeiro pelas ilhas, com toda a especificidade do ambiente de cada uma delas. No último dia, acalenta-se a melancolia da partida e num derradeiro apontamento, questiona-se o autor:

Veneza é água?

Não.

Veneza é música e é luz.(p. 52)

Deste modo, numa sinuosa experiência de sinestesias estetizantes que embriagam a alma, reabilitam-se todas as dimensôes que o mito veneziano implicava para uma plêiade de escritores que o ajudaram a configurar e que atingiu no fim-de-século a sua máxima expressão e que Eduardo Pitta, por conseguinte, habilmente dinamiza.

Por último, com De Riba-Côa a Roma. Uma Viagem no Tempo... de 1676, de Alcides Gouveia, assistimos a uma incursão na esfera do romance histórico em que a viagem é o elemento estruturante da diegese. Aliás, no prefácio da responsabilidade de António Bagão Félix, afirma-se perentoriamente:

"De Riba-Côa a Roma" - que o autor situa entre o conto alongado e o romance curto - é produto da sua personalidade insaciável de juntar conhecimento ao conhecimento e de escrever com gosto indisfarçável. É também uma homenagem senciente às suas raízes de uma portugalidade radicada nas entranhas do interior do País. É, igualmente, um 
itinerário que, através de um facto verídico de outrora, nos convida a uma digressão no tempo e a fazer a ponte entre a memória de um passado ali tão perto, as inquietações de hoje, as consequências da "aldeia global" e da prevalência da tecnocracia ambivalente. [...]

No livro, o autor percorre épocas e modos. Itinerários e atalhos. Realidade de sonhos. Amargores e gostos. Angústias e esperança. Fé e descrenças. Inconformismo e lucidez. Amores e humores. Idealismo e pragmatismo. Heroísmo e traições. Lendas e história.

Uma viagem dentro da viagem. Porque o tempo não tem tempo. $\mathrm{Ou}$ melhor, tem a medida que lhe damos. Na transitoriedade do que convencionámos chamar presente, na métrica de um futuro ainda por encontrar e na memória de um passado que é por onde tudo passa para ser inexoravelmente nosso.(Gouveia, 2014, pp. 9-10)

Trata o enredo de uma viagem até Roma realizada por um cura e um mestre-escola de aldeia, mais propriamente de $\mathrm{Vi}$ lar de Amargo, em terras de Foz-Côa. Um crime cometido na igreja matriz da terra ditara a interdição do templo. Restava apenas ao velho pároco empreender a jornada ao Vaticano a fim de levantar a dita interdição. Nas palavras de Teolinda Gersão,

Um crime passional acontecido em Riba-Côa, em 1676, é o motivo central deste romance. O tema histórico - o crime comprovadamente aconteceu neste local e data - transporta-nos até ao século XVII e leva-nos até Roma, numa viagem de peripécias várias. Mas o romance não fica na época narrada: é um livro do século XXI, que nos confronta com questóes profundamente actuais, como o papel da igreja na sociedade e a importância da literatura como memória e denúncia...(Gouveia, 2014, contracapa)

Para tão longa expedição, socorre-se o bom do pároco da companhia do amigo de longa data, o professor das primeiras letras lá do lugar. E os animados diálogos entre ambos travados abrem incursões nos mais variados campos: para além 
da vida social do século XVII, da pertinência e importância pública da linguagem, dos rituais, da rotina do bem dizer e da maledicência, bem como da psicologia social, comentam-se as muitas terras e cidades, os monumentos, costumes e linguajares com que ao longo do caminho se confrontam. Por isso, considera ainda Bagão Félix que "Esta obra é uma espécie de manual didáctico de história, arte, linguística e geografia, que os diálogos entre o Padre e o Professor nos fornecem, a propósito de cada parcela da viagem entre Vilar de Amargo e Roma” (p. 11). Esta é, por conseguinte, "uma viagem feita de memória e de afecto. De tradição e de convicção" (Bagão Félix, in Gouveia, 2014, 11).

Depois de atravessarem a Espanha, de Salamanca aos Pirenéus, aproveitando, em parte, os caminhos dos peregrinos de S. Tiago, montados no Relinchão, na Ruça e na Pileca, e de seguirem com um grupo de romeiros até quase às portas de Roma, em que se contavam dois estudantes da Universidade de Bolonha, o percurso italiano seguiu por Balzi Rossi, Ventimiglia, San Remo, Albenga, Génova, Portofino, Livorno, Piombino, Tarquínia, Civitavecchia, Ostia Antica e Roma. Uma vez chegados ao destino, ambos visitam as basílicas da Cidade Eterna e, de seguida, cada um opta por seguir um caminho adequado aos respectivos interesses. Enquanto o Professor visita os monumentos da Roma imperial, o Padre João faz o percurso dos lugares caros à cristandade, até que desaparece depois de sair das catacumbas e só é encontrado dias passados num hospital em precário estado de saúde. Nomeado cónego em reconhecimento dos esforços despendidos, lá fica até falecer, pelo que o mestre-escola se vê na contingência de regressar solitário a Vilar de Amargo. Depois de cumpridas as obrigaçóes, de outorgar os documentos que ditavam o levantamento da interdição da matriz e de entregar as relíquias de Santo Eugénio e Santo Augusto, de que fora portador, só mais tarde, e por mero acaso, acaba por descobrir os intervenientes no crime que originara a malograda viagem. 
Recorrendo, deste modo, a estratégias dos relatos de viagens de romeiros e dos estudantes que buscavam o saber em distantes universidades italianas desde a Idade Média, procura-se adequá-las a uma realidade em que a viagem por terra constituía ainda uma desafiante aventura. Claro que, para além disso, reactiva-se a sua importância no âmbito dos códigos narrativos.

Por conseguinte, deparamos aqui com três relatos que já muito se distinguem dos da primeira metade do século XX, estes ainda muito próximos do modelo dos tratados de bem conduzir o leitor na viagem e levá-lo a assumir as escolhas mais adequadas perante as alternativas com que se vê confrontado. No que diz respeito à viagem a Itália, são os relatos de Agustina BessaLuís, Embaixada a Calígula, de 1960, seguido do de Sophia de Mello Breyner, "Veneza eterna", este já de 1997, que representam o virar de página, passando a literatura de viagens a enriquecer-se com uma dimensão reflexiva mais densa.

Assim sendo, perante os relatos aqui considerados, pode-se, pois, concluir que, quer através da revisitação do passado, quer do confronto com a experiência da realidade italiana, o aproveitamento de preceitos literários antes usados em relatos de viagens do passado é agora feito a uma nova luz, mais crítica e elaborada; que a viagem é sempre motivo de formação e enriquecimento, mas a dimensão psicológica do viajante adquire uma nova dimensão e maior ênfase; e que dos encontros de culturas sempre se colheram frutos que fizeram desabrochar ideias e florescer as diferentes áreas do saber, além de contribuírem para a valorização de cada indivíduo na sua dimensão mais intrinsecamente humana. 